\title{
Diabetic foot: prevalence, knowledge, and foot self-care practices among diabetic patients in Dar es Salaam, Tanzania - a cross-sectional study

Faraja S. Chiwanga ${ }^{1 *}$ and Marina A. Njelekela ${ }^{1,2}$

\begin{abstract}
Background: At the time of diagnosis, more than $10 \%$ of people with type 2 diabetes mellitus have one or two risk factors for a foot ulceration and a lifetime risk of $15 \%$. Diabetic foot ulcers can be prevented through well-coordinated foot care services. The objective of this study was to determine knowledge of foot care and reported practice of foot self-care among diabetic patients with the aim of identifying and addressing barriers to preventing amputations among diabetic patients.
\end{abstract}

Methods: Patients were randomly selected from all public diabetic clinics in Dar es Salaam. A questionnaire containing knowledge and foot care practice questions was administered to all study participants. A detailed foot examination was performed on all patients, with the results categorized according to the International Diabetes Federation foot risk categories. Statistics were performed using SPSS version 14.

Results: Of 404 patients included in this study, $15 \%$ had foot ulcers, $44 \%$ had peripheral neuropathy, and $15 \%$ had peripheral vascular disease. In multivariate analysis, peripheral neuropathy and insulin treatment were significantly associated with presence of foot ulcer. The mean knowledge score was 11.2 \pm 6.4 out of a total possible score of 23. Low mean scores were associated with lack of formal education (8.3 \pm 6.1$)$, diabetes duration of $<5$ years (10.2 \pm 6.7$)$ and not receiving advice on foot care $(8.0 \pm 6.1)$. Among the 404 patients, $48 \%$ had received advice on foot care, and $27.5 \%$ had their feet examined by a doctor at least once since their initial diagnosis. Foot self-care was significantly higher in patients who had received advice on foot care and in those whose feet had been examined by a doctor at least once.

Conclusions: The prevalence of diabetic foot is high among patients attending public clinics in Dar es Salaam. There is an urgent need to establish coordinated foot care services within the diabetic clinic to identify feet at risk, institute early management, and provide continuous foot care education to patients and health care providers.

Keywords: Diabetes, Diabetic foot, Foot care

\section{Background}

It is estimated that, at the time of diagnosis of type 2 diabetes mellitus, more than $10 \%$ of patients have one or two risk factors for foot disease, such as peripheral neuropathy $(\mathrm{PN})$ or peripheral vascular disease (PVD) [1]. The burden of diabetic foot disease is expected to increase given the increasing global prevalence of T2DM. Worldwide, $3 \%-10 \%$ of people with diabetes

\footnotetext{
* Correspondence: fschiwanga@yahoo.com

${ }^{1}$ Muhimbili National Hospital, Kalenga Street, Upanga, P.O Box 65000, Dar es Salaam, Tanzania

Full list of author information is available at the end of the article
}

have a foot ulcer (DFU); the lifetime risk for developing DFU is $15 \%$ [1]. Rates of foot ulceration in Africa vary between regions and have been estimated to be between $4 \%$ and $19 \%$ [2].

Several studies have shown that a majority of people with diabetes do not receive guideline-recommended foot care, including regular foot examinations. [3] In a study conducted by Basu et al. in the United Kingdom, $33 \%$ of people with diabetes did not recall receiving information about foot care [4]. In a study conducted at the Muhimbili National Hospital (MNH) diabetic clinic, $87 \%$ of patients reported never inspecting their feet, and 
$66 \%$ reported they were not interested in further knowledge of diabetes foot care [5].

Among the complications of diabetes, lower limb amputation is considered to be potentially preventable. [6] Most lower limb amputations in patients with diabetes are preceded by a foot ulcer, whose risk factors apart from PVD and PN, are barefoot walking, inappropriate footwear, poor foot hygiene and delay in seeking medical attention [7]. These non-traditional risk factors can be modified if identified early, and if patients have adequate knowledge of foot care and put that knowledge into practice. [7] In recent years, the level of interest and knowledge about DFU has grown considerably, as witnessed by the development of an international consensus, clinical guidelines to be used in both prevention and treatment of diabetic foot, and improvements in evidence-based clinical practice. All patients, if given proper guidance and education regarding foot care, should be able to make significant improvements in their foot care. Evidence that foot care education alone prevents DFU and amputation has been inconsistency due to lack of high quality randomized trials. However, this lack of evidence is not evidence of no effect $[8,9]$. Current guidelines for standardized care of diabetic patients recommend annual screening for high risk feet. Those identified as high risk should receive enhanced and focused foot care education [10].

Although there is a large amount of literature on diabetic foot and the importance of foot care, there are limited published data on knowledge and practices of foot care among diabetic patients in Sub-Saharan Africa, specifically in Tanzania. Thus, this study was conducted to determine the current prevalence of DFU and to assess the knowledge and practices of foot care among patients who attend public diabetic clinics in Dar es Salaam, Tanzania. The information obtained will inform the current situation in relation to diabetic foot prevention strategies, and will help to improve quality of care for diabetic patients to reduce the burden associated with diabetes foot complications. Educating patients is likely to be effective if we are aware of their current knowledge and practices on foot care.

\section{Methods}

This was a cross-sectional descriptive study, which included 404 patients from public diabetic clinics in Dar es salaam, Tanzania. Data was collected in 2007 from diabetic clinics at $\mathrm{MNH}$ and the three municipal hospitals in Dar es Salaam, namely Mwananymala, Amana, and Temeke. A systematic sampling technique was used to select participants in each clinic which was visited once a week. No patient declined to join the study, patients who could not sign consent form because of being under age, were excluded from the study. Patients, who agreed to enter the study but could not wait to have their feet examined, were given an appointment on a later date.

A standard questionnaire was used to enquire about knowledge and practice of foot care. Knowledge was assessed through open-ended questions, without multiple choice answers, as suggested by K. Kaliyaperumal in the guideline for conducting a knowledge, attitude, and practice study [11]. Patients were categorized according to their response on pre-determined answers. Foot self-care practices were adopted from the Summary of Diabetes Self-Care Activities (SDSCA) measure, which identifies the number of days in the past week a person has performed diabetes self-care activities [12]. Each subject underwent foot examination to identify $\mathrm{PN}$, PVD, DFU, or any other pathology that would be used to categorize the feet into risk categories.

Modified Neuropathy Disability Score (NDS) [13] was used to assess PN, whereby absent pain, vibration, and pressure senses were assigned 1 point each and 0 point where they were present. Ankle reflexes were assigned 2, 1 , and 0 points for absent, present with reinforcement, and present without reinforcement, respectively. Severity of PN was graded after summation of all the assigned points and classified as no neuropathy (score 0), mild neuropathy (score 1-3), moderate neuropathy (score 4-7) and sever neuropathy (score $>7$ ). Total score of Ankle brachial pressure index (ABPI) was measured using a handheld laser Doppler machine with ABPI of 0.9 as a cutoff point [14]. PVD was defined as ABPI of $<0.9$; arterial calcification was defined as ABPI of $>1.3$.

Foot risk status was assigned using IDF global guideline for type 2 diabetes, where "no added risk" defines a foot with no any risk factor, "at risk" foot has one risk factor without previous history of DFU or amputation and "high risk" foot has more than one risk factor or previous history of DFU or amputation [15].

\section{Statistical analysis}

All data were analyzed using SPSS statistical package version 14. Comparison between two groups was done by using Pearson correlation (chi-square) and Fisher's exact test for categorical variables. Univariate and multivariate logistic regressions were done to determine odds ratios. For continuous variables, student's $t$-test or analysis of variance was used to assess difference between groups. For all these statistics, a p-value of less than 0.05 was considered significant.

\section{Ethical considerations}

Ethical approval was granted by the Research and Publications Ethics committee of the Muhimbili University of Health and Allied Sciences. Permission to collect data was granted from the hospitals authorities. Consent forms were written in "Swahili" language, patients were 
given the consent to read and sign, and those who could not read it was explained to them and made a thumb print. To maintain confidentiality, all questionnaires were coded and did not bear patients names.

\section{Results}

\section{Magnitude of risk factors}

A total of 404 patients were included in this study, of which $55.4 \%$ were female. Demographic and socioeconomic characteristics of the population are shown in Table 1. Point prevalence of DFU was 15.3 \% (95 \% CI: 2.17-5.92). Socioeconomic status did not differ between patients with DFU and those without DFU.

Table 2 demonstrates the magnitude of risk factors in univariate and multivariate analysis. In univariate logistic regression analysis, age $>55$ years, insulin treatment, and PN all increased the likelihood of having DFU. Alcohol intake was associated with a lower likelihood of DFU. Variables with p-value of $<0.1$ were further analyzed in the multivariate logistic regression model. In multivariate analysis, PN and insulin treatment were significant predictors of DFU. Patients with moderate PN were eight times more likely to have DFU, and those with severe neuropathy were 24 times more likely to develop ulcers. Patients on insulin treatment were twice more likely to have DFU than those on oral or non-pharmacological management.

\section{Knowledge of foot care}

Knowledge of diabetic foot risk factors and foot care among the study population is shown in Table 3 . The total score for all knowledge questions was 23. Scores from patients' responses ranged from $0-23$, with a mean score of $11.2 \pm 6.4$ S.D (95 \% CI: $10.58-11.83$ ). The mean score was similar among patients with DFU and those without DFU. Higher level of education, longer duration of T2DM, and having received information on foot care were associated with higher mean scores.

In this study, 194 patients (48.0\%) had received information about foot care. Duration of diabetes had no effect on whether patients received information or not $(\mathrm{p}=$ 0.158). The majority of patients received education from nurses $(83.5 \%$ ); only $16.6 \%$ received foot care information from doctors; and $6.2 \%$ were educated by other sources, such as the media.

Table 1 Demographic and socioeconomic characteristics of diabetic patients by presence or absence of diabetic foot ulcer

\begin{tabular}{|c|c|c|c|c|}
\hline \multirow[t]{2}{*}{ Characteristics } & Total population & DFU present & No DFU & \multirow{2}{*}{$\begin{array}{l}\mathrm{p} \text {-value } \\
X^{2} / \text { Fisher's test }\end{array}$} \\
\hline & $\mathrm{N}=404(\%)$ & $N=62$ & $N=342$ & \\
\hline Age (mean \pm S.D) & $53.6 \pm 12.7$ & $56.4 \pm 13.1$ & $53.1 \pm 9.9$ & 0.060 \\
\hline \multicolumn{5}{|l|}{ Gender } \\
\hline Female & $224(100)$ & $33(14.7)$ & $191(85.3)$ & \multirow[t]{2}{*}{0.702} \\
\hline Male & $180(100)$ & $29(16.1)$ & $151(83.9)$ & \\
\hline \multicolumn{5}{|l|}{ Marital status } \\
\hline Married & $305(100)$ & $49(16.1)$ & $256(83.9)$ & \multirow[t]{3}{*}{0.455} \\
\hline Never married & $28(100)$ & $2(7.1)$ & $26(92.9)$ & \\
\hline Previously married & $71(100)$ & $11(15.5)$ & $60(84.8)$ & \\
\hline \multicolumn{5}{|l|}{ Education level } \\
\hline No formal education & $46(100)$ & $10(21.7)$ & $36(78.3)$ & 0.519 \\
\hline Primary education & $253(100)$ & $35(13.8)$ & 218(86.2) & \multirow[t]{3}{*}{$* 0.715$} \\
\hline Secondary and vocational & $87(100)$ & $14(16.1)$ & $73(83.9)$ & \\
\hline Post-secondary education & $18(100)$ & $3(16.7)$ & 15 (83.3) & \\
\hline \multicolumn{5}{|l|}{ Smoking } \\
\hline Currently smoking & $13(100)$ & $3(23.1)$ & $10(76.9)$ & \multirow[t]{3}{*}{0.564} \\
\hline Past smoker & $78(100)$ & $13(16.7)$ & $65(83.3)$ & \\
\hline Never smoked & $313(100)$ & $46(14.7)$ & $267(85.3)$ & \\
\hline \multicolumn{5}{|l|}{ Alcohol Intake } \\
\hline Currently drinking & $42(100)$ & $1(2.4)$ & $41(97.6)$ & \multirow[t]{3}{*}{0.048} \\
\hline Past drinker & $142(100)$ & $24(16.9)$ & $118(83.1)$ & \\
\hline Never drank alcohol & $220(100)$ & 37 (16.8) & $183(83.2)$ & \\
\hline
\end{tabular}

*p-value for trend 
Table 2 Univariate and multivariate analysis of predictors of diabetic foot ulcers in diabetic patients $(N=404)$

\begin{tabular}{|c|c|c|c|c|}
\hline \multirow{2}{*}{$\begin{array}{l}\text { Patient } \\
\text { characteristics }\end{array}$} & Univariate & \multirow[t]{2}{*}{$p$-value } & Multivariate & \multirow{2}{*}{$\begin{array}{l}p- \\
\text { value }\end{array}$} \\
\hline & O.R (95\% Cl) & & O.R (95\% Cl) & \\
\hline \multicolumn{5}{|l|}{ Age: } \\
\hline$<55$ & 1.00 & 0.022 & & 0.473 \\
\hline$>55$ & $1.91(1.10-3.30)$ & & & \\
\hline \multicolumn{5}{|l|}{ Gender: } \\
\hline Female & 1.00 & 0.702 & & \\
\hline Male & $0.90(0.52-1.55)$ & & & \\
\hline \multicolumn{5}{|l|}{ Smoking: } \\
\hline Never & 1.00 & 0.413 & & \\
\hline Current & $1.74(0.46-6.57)$ & 0.664 & & \\
\hline Past smoker & $1.16(0.59-2.78)$ & & & \\
\hline \multicolumn{5}{|l|}{ Alcohol: } \\
\hline Current & 1.00 & 0.041 & & 0.322 \\
\hline Past drinker & $8.34(1.09-63.60)$ & 0.040 & & 0.718 \\
\hline Never & $8.29(1.10-62.17)$ & & & \\
\hline \multicolumn{5}{|l|}{ Education: } \\
\hline No formal education & 1.00 & 0.172 & & \\
\hline Primary education & $0.58(0.26-1.27)$ & 0.422 & & \\
\hline Secondary education & $0.69(0.28-1.71)$ & 0.651 & & \\
\hline Post-secondary & $0.72(0.17-2.99)$ & & & \\
\hline \multicolumn{5}{|l|}{ Treatment: } \\
\hline $\begin{array}{l}\text { Oral/non- } \\
\text { pharmacologic }\end{array}$ & 1.00 & 0.013 & $2.25(1.17-4.32)$ & 0.015 \\
\hline Insulin & $2.04(1.16-3.59)$ & & & \\
\hline \multicolumn{5}{|l|}{ PVD: } \\
\hline No & 1.00 & 0.660 & & \\
\hline Yes & $1.18(0.57-2.4)$ & & & \\
\hline \multicolumn{5}{|l|}{ PN: } \\
\hline No neuropathy & 1.00 & 0.387 & 1.00 & 0.420 \\
\hline Mild neuropathy & $2.03(0.41-10.1)$ & $<0.001$ & $1.94(0.4-9.7)$ & $<0.001$ \\
\hline $\begin{array}{l}\text { Moderate } \\
\text { neuropathy }\end{array}$ & $8.11(3.3-19.9)$ & $<0.001$ & $8.14(3.3-20.2)$ & $<0.001$ \\
\hline Severe neuropathy & $23.46(10.2-54.0)$ & & $24.19(10.4-56.3)$ & \\
\hline \multicolumn{5}{|l|}{ Previous DFU: } \\
\hline No & 1.00 & $<0.001$ & & 0.185 \\
\hline Yes & $3.23(1.85-5.6)$ & & & \\
\hline \multicolumn{5}{|l|}{ Duration of DM: } \\
\hline$<5$ year & 1.00 & 0.208 & & 0.552 \\
\hline 5-10 year & $1.49(0.8-2.7)$ & 0.068 & & 0.962 \\
\hline$>10$ year & $1.94(0.9-3.9)$ & & & \\
\hline \multicolumn{5}{|l|}{ Foot deformity: } \\
\hline No & 1.00 & 0.052 & & 0.887 \\
\hline Yes & $2.04(0.9-4.2)$ & & & \\
\hline
\end{tabular}

Table 3 Mean scores of knowledge on diabetes foot care among diabetic patients

\begin{tabular}{|c|c|c|c|}
\hline Characteristics & $\begin{array}{l}\text { Total population } \\
\mathrm{N}=404\end{array}$ & Mean (SD) & p-value \\
\hline \multicolumn{4}{|l|}{ Age } \\
\hline$<55$ & 211 & $11.5(6.4)$ & \multirow[t]{2}{*}{0.343} \\
\hline$>55$ & 193 & $10.9(6.3)$ & \\
\hline \multicolumn{4}{|l|}{ Gender } \\
\hline Female & 224 & $11.0(6.7)$ & \multirow[t]{2}{*}{0.435} \\
\hline Male & 180 & $11.5(6.0)$ & \\
\hline \multicolumn{4}{|l|}{ Education level } \\
\hline No formal education & 46 & $8.3(6.1)$ & \multirow[t]{4}{*}{0.002} \\
\hline Primary education & 253 & $11.3(6.4)$ & \\
\hline Secondary & 87 & $12.7(6.1)$ & \\
\hline Post-secondary & 18 & $10.1(6.8)$ & \\
\hline \multicolumn{4}{|c|}{ Duration of T2DM (years) } \\
\hline$<5$ & 198 & $10.2(6.7)$ & \multirow[t]{3}{*}{0.002} \\
\hline $5-10$ & 135 & $12.7(5.7)$ & \\
\hline$>10$ & 71 & $11.2(6.1)$ & \\
\hline \multicolumn{4}{|c|}{ Received advice on foot care } \\
\hline Yes & 194 & $14.1(5.3)$ & \multirow[t]{2}{*}{$<0.001$} \\
\hline No & 210 & $8.0(6.1)$ & \\
\hline \multicolumn{4}{|l|}{$\begin{array}{l}\text { Source of information } \\
\text { (who received advice } \\
\text { on foot care) }\end{array}$} \\
\hline Doctor & 30 & $14.8(4.9)$ & \multirow[t]{3}{*}{0.538} \\
\hline Nurse & 152 & $13.6(5.4)$ & \\
\hline Others & 12 & $13.7(6.4)$ & \\
\hline \multicolumn{4}{|l|}{ Previous history DFU } \\
\hline Yes & 107 & $11.6(5.9)$ & \multirow[t]{2}{*}{0.490} \\
\hline No & 297 & $11.1(6.6)$ & \\
\hline \multicolumn{4}{|l|}{ Current DFU } \\
\hline Yes & 64 & $11.0(6.0)$ & \multirow[t]{2}{*}{0.732} \\
\hline No & 340 & $11.3(6.5)$ & \\
\hline
\end{tabular}

\section{Foot care practices}

Table 4 summarizes foot care practices for study patients by risk category. Foot self-inspection was done regularly (6-7 days a week) by $37.9 \%$ of patients, the majority of whom already had DFU.

Table 5 shows that patients who had at least one foot examination performed by a doctor were more likely to care for their feet than those who had not. However, only 111 patients (27.5\%) reported having their feet examined by a doctor at least once since their initial diagnosis.

\section{Discussion}

Risk factors for diabetic foot ulcer

Among persons with diabetes, the lifetime risk of developing DFU has been estimated to be $15 \%$; however, 
Table 4 Foot care practices of diabetic patients at the time of interview by risk category

\begin{tabular}{|c|c|c|c|c|c|c|}
\hline \multirow[t]{2}{*}{ Practices } & Total & No added risk & At risk & High risk & DFU & \multirow[t]{2}{*}{ p-value } \\
\hline & $N=404$ & $N=136$ & $N=108$ & $N=98$ & $N=62$ & \\
\hline \multicolumn{7}{|c|}{ Foot care practices performed for $6-7$ days } \\
\hline Inspecting feet & $153(37.9)$ & $57(41.9)$ & $40(37.0)$ & $33(33.7)$ & $23(37.1)$ & 0.631 \\
\hline Inspecting shoes & $149(36.9)$ & $58(42.6)$ & $41(38.0)$ & $31(31.6)$ & 19 (30.6) & 0.241 \\
\hline Washing feet & $378(92.8)$ & $127(93.4)$ & $101(97.2)$ & $85(89.8)$ & $59(95.2)$ & 0.573 \\
\hline Drying between toes & $213(52.7)$ & 77 (56.6) & $58(53.7)$ & $48(49.0)$ & $30(48.4)$ & 0.596 \\
\hline Not soaking feet & $374(92.6)$ & $129(94.9)$ & $99(91.7)$ & $94(95.9)$ & $53(85.5)$ & 0.091 \\
\hline \multicolumn{7}{|l|}{ Walking barefoot: } \\
\hline Outside the house & $236(58.4)$ & $84(61.8)$ & $60(55.6)$ & $53(54.1)$ & $39(62.9)$ & 0.699 \\
\hline Inside the house & $53(13.1)$ & 18 (13.2) & $14(13.0)$ & $17(17.3)$ & $4(6.5)$ & 0.493 \\
\hline Use of sharp instruments to cut nails & $351(86.9)$ & $114(83.8)$ & $91(84.3)$ & 89 (90.8) & 57 (91.9) & 0.213 \\
\hline
\end{tabular}

recent studies have shown that lifetime incidence could be as high as $25 \%[1,5]$. In this study, the prevalence of DFU among patients attending public diabetic clinics in Dar es Salaam was $15 \%$. A similar prevalence (15\%) was reported by Abbas et al. among diabetic patients admitted to MNH from 1997 to 1998 [16], which raises concerns that more efforts are needed to prevent DFU.

PN has been described as the most common component cause in the pathway to diabetic foot ulceration [17]. For the past 10 years, published data on prevalence of PN in Africa has ranged from $25 \%$ in Tanzania to $84 \%$ in Algeria [2]. Part of reason for the massive difference in the prevalence of peripheral neuropathy in Africa is the heterogeneity of the studies and differences in diagnostic criteria. In this study, the prevalence of PN was $44 \%$, while the prevalence of PN among patients with foot ulcer was $94 \%$. Patients with moderate PN were eight times more likely to have foot ulcers, while those with severe PN were 24 times more likely than those with no neuropathy. These findings signify the importance of education on caring for insensate feet to prevent minor trauma, which is a significant factor in the development of foot ulcers. Patients need to be educated on the importance of glycaemic control in order to prevent long term diabetes complications which include PN. Emphasis should be placed on older patients and those with longer duration of diabetes since they are more prone to have $\mathrm{PN}$ and are likely to have other complications, such as retinopathy, that may put them at even greater risk of injury $[18,19]$.

PVD was present in $15 \%$ of patients, and was not associated with DFU in this study. Contrary to this finding, Boyko et al. identified ABPI to be an independent risk factor for developing foot ulcer in the Seattle diabetic foot study [20].

\section{Knowledge of foot care}

The importance of foot care knowledge in preventing foot ulcers in diabetic patients is a widely accepted fact; however, over half of the diabetic patients in this study reported they had never received information regarding foot care. Level of knowledge on foot care was similar among patients with DFU and those without DFU. Lack of knowledge about diabetic foot among health care providers, shortage of staff, and overcrowding of clinics can partly explain these findings. Most clinics are run once or twice per week-with daily attendance of about 50 patients-with two nurses and two doctors. To arrange an individualized educational session is usually difficult,

Table 5 Foot care practices of patients by whether they had feet examined by doctor or not

\begin{tabular}{llll}
\hline $\begin{array}{l}\text { Foot care practices done in 6-7 } \\
\text { days and foot risk behaviors }\end{array}$ & Feet examined & Feet not examined & $\begin{array}{l}\mathrm{p}- \\
\text { value }\end{array}$ \\
\hline Inspecting feet & $58(52.3)$ & $\mathrm{N}=210$ & $95(32.4)$ \\
Inspecting shoes & $53(47.7)$ & $96(32.8)$ & $<0.001$ \\
Washing feet & $107(96.4)$ & $268(91.5)$ & 0.005 \\
Drying between toes & $71(64.0)$ & $142(48.5)$ & 0.087 \\
Not soaking & $94(84.7)$ & $280(95.5)$ & 0.005 \\
Never walking barefoot & $48(43.2)$ & $67(22.9)$ & $<0.001$ \\
Use of sharp instruments to cut nails & $11(9.9)$ & $42(14.3)$ & $<0.001$ \\
\hline
\end{tabular}


and providing an appointment on a separate day incurs a financial burden on the patient. Education on foot care is usually given universally without being individualized according to the foot risk of the patients.

The mean knowledge score was influenced by level of education, duration of diabetes, and advice on foot care. Patients with no formal education had lower mean scores, as did those with diabetes duration of less than 5 years and those who had not received advice on foot care. Patients with longer duration of diabetes are more likely to have repeated education sessions, which may favor their knowledge scores. Khamseh et al. also found that low knowledge scores were attributed to low level of education and to not receiving advice on foot care; however, the duration of diabetes had no effect in his study [21]. People with a higher education level are more likely to read and to obtain information regarding foot care in addition to any information provided to them in the clinics.

In the diabetic outpatient clinics, regular educational classes are provided on a day separate from the clinic day. These classes are open to all patients with diabetes, but emphasis is placed on attendance by newly diagnosed patients. Patients may only attend once, shortly after they are diagnosed, and thereafter not see the need to attend. Moreover, patients may feel the education is not worth the cost (i.e., patients have to incur the cost of transportation to/from the clinic on a separate day). Those with foot problems, especially painful PN, may not be able to visit the clinic frequently. These patients may opt to make just one trip, often the one in which they will be getting prescriptions for their medications. For these reasons, Ward et al. recommended a flexible schedule for diabetes education, offering education at any time for the maximum convenience of patients rather than focusing on health care provider's convenience, preferably integrating it into normal consultation [22]. Educational programs should also address psychological and cultural factors that often underlie self-care behavior [23].

\section{Foot self-care practices}

In this study, foot self-care practices were not performed by many patients, even in the groups at high risk for developing foot ulcers. The majority of patients did not inspect their feet regularly or inspect the insides of their shoes. Risky behaviors, such as cutting toenails with sharp instruments (e.g., razor blade or knife) were performed by over $80 \%$ of study patients. These behaviors can cause minor injuries especially if a patient has $\mathrm{PN}$ or retinopathy as part of diabetes complications.

Foot self-care was practiced similarly among all risk categories of patients, but improved among those who had received advice on foot care and those whose feet have been examined by a doctor at least once. Bell et al. made similar observations in evaluating long-term diabetes self-management among an elderly population in the United States [24]. They found the following patients were more likely to practice foot self-care than those who did not meet these criteria: patients who had received advice on foot care, and patients who had their feet examined by a doctor or were shown by a doctor how to examine their feet. This fact should alert physicians treating patients with diabetes to always have interest in evaluating the patients' feet as the physician's attention and behavior has a positive effect on their patients' foot care practice.

\section{Conclusions}

The prevalence of diabetic foot ulcers is high among patients attending public diabetic clinics in Dar es Salaam. Peripheral neuropathy is the major risk factor for foot ulcer in this population. Avoidance of injuries to an insensate limb and appropriate foot care practice by both patients and health care providers may reduce DFU. Knowledge of foot care is low among patients with diabetes. Their knowledge can be improved by education and proper foot care modeling by health care providers. It is essential to assess patients' beliefs and behavior so as to offer education and utilize educational methods that facilitates them to care for their feet efficiently.

There is an urgent need to educate and raise awareness among doctors regarding the importance of identifying risk factors for foot ulcers in patients with diabetes. Knowledge alone however, does not always lead to change in behavior and in Africa there are several other challenges that lead to poor foot care including non-existent podiatry services, lack of programs for health care professionals and lack of surveillance mechanism.

Health care facilities should incorporate foot care services among other routine services being provided to diabetic patients in order to identify patients with risk factors and those who already have foot ulcers. There is a need for continuous education on foot care to improve patients' knowledge of risks and foot self-care practices.

\section{Abbreviations \\ ABPI: Ankle brachia pressure index; IDF: International Diabetes Federation; DFU: Diabetic foot ulcer; MNH: Muhimbili National Hospital; PN: Peripheral neuropathy; PVD: Peripheral vascular diseases; T2DM: Type 2 Diabetes.}

\section{Competing interests}

The authors declare that they have no competing interest.

\section{Authors' contributions}

FSC - Study design, data collection, data analysis and interpretation, prepared first and final draft of the manuscript. MAN - Study design, data interpretation and revising the manuscript. Both authors read and approved the final manuscript. All authors read and approved the final manuscript. 


\section{Author details}

${ }^{1}$ Muhimbili National Hospital, Kalenga Street, Upanga, P.O Box 65000, Dar es Salaam, Tanzania. ${ }^{2}$ Muhimbili University of Health and Allied Sciences, Mindu Street, Upanga, P.O Box 65001, Dar es Salaam, Tanzania.

Received: 30 December 2014 Accepted: 1 June 2015 Published online: 05 June 2015

\section{References}

1. Andrew J, Gunne R, Jan A. The global burden of diabetes foot disease. Lancet. 2005;366:1719-24

2. Abbas ZG, Archibald LK. Epidemiology of the diabetic foot in Africa. Med Sc Monit. 2005;11:262-70.

3. Barshes NR, Sigireddi M, Wrobel JS, Mahankali A, Robbins JM, Kougias $P$, et al. The system of care for the diabetic foot: objectives, outcomes, and opportunities. Diabet Foot Ankle. 2013:4:21847.

4. Basu S, Hadley J, Tan RM, Williams J, Shearman CP. Is there enough information about foot care among patients with diabetes? Int J Low Extrem Wounds. 2004;3:64-8.

5. Wikblad K, Smide B, Bergstrom A, Kessi J, Mugusi F. Outcome of clinical foot examination in relation to self-perceived health and glycaemic control in a group of urban Tanzanian diabetic patients. Diabetes Res Clin Pract. 1997:37:185-92.

6. Morey-Vargas OL, Smith SA. BE SMART: strategies for foot care and prevention of foot complications in patients with diabetes. Prosthet Orthot Int. 2015;39:48-60

7. Abbas ZG, Archibald LK. Challenges for management of the diabetic foot in Africa: doing more with less. Int Wound J. 2007:4:305-13.

8. Dorresteijn JA, Kriegsman DM, Assendelft WJ, Valk GD. Patient education for preventing diabetic foot ulceration. Cochrane Database Syst Rev. 2010;5, CD001488.

9. Dorresteijn JA, Valk GD. Patient education for preventing diabetic foot ulceration. Diabetes Metab Res Rev. 2012;28 Suppl 1:101-6.

10. Boulton AJ, Armstrong DG, Albert SF, Frykberg RG, Hellman R, Kirkman MS, et al. Comprehensive foot examination and risk assessment: a report of the task force of the foot care interest group of the American Diabetes Association, with endorsement by the American Association of Clinical Endocrinologists. Diabetes Care. 2008;31:1679-85.

11. Kaliyaperumal K. Guideline for conducting a knowledge, attitude, and practice (KAP) study. Community Ophthalmology. 2004;4:7-9.

12. Toobert D, Hampson S, Glasgow R. The summary of diabetes self-care activities measure: results from 7 studies and a revised scale. Diabetes Care. 2000;23:943-50.

13. Miranda-Palma B, Sosenko JM, Bowker JH, Mizel MS, Boulton AJ. A comparison of the monofilament with other testing modalities for foot ulcer susceptibility. Diabetes Res Clin Pract. 2005;70:8-12.

14. Aboyans V, Criqui MH, Abraham P, Allison MA, Creager MA, Diehm C, et al. Measurement and interpretation of the ankle-brachial index: a scientific statement from the American Heart Association. Circulation. 2012;126:2890-909.

15. IDF. Global guideline for type 2 diabetes. Diabetes Res Clin Pract. 2014:104:1-52.

16. Gulam-Abbas Z, Lutale JK, Morbach S, Archibald LK. Clinical outcome of diabetes patients hospitalized with foot ulcers, Dar es Salaam. Tanzania Diabet Med. 2002;19:575-9

17. Reiber GE, Vileikyte L, Boyko EJ, Aguila M, Smith DG, Lavery LA, et al. Causal pathways for incident lowe-extremity ulcers in patients with Diabetes from two settings. Diabetes Care. 1999:22:157-62.

18. Van Gils CC, Stark LA. Diabetes mellitus and the elderly: special considerations for foot ulcer prevention and care. Ostomy Wound Manage. 2006;52:50-2.

19. Pataky Z, Vischer U. Diabetic foot disease in the elderly. Diabetes Metab. 2007:33 Suppl 1:S56-65.

20. Boyko E, Ahron J, Stensel V, Forsberg R, Davignon D, Smith D. Prospective study of risk factors for diabetic foot ulcer. The Seattle Diabetic Foot Study. Diabetes Care. 1999;22:1036-42.

21. Khamseh ME, Vatankhah N, Baradaran HR. Knowledge and practice of foot care in Iranian people with type 2 diabetes. Int Wound J. 2007:4:298-302.
22. Ward A, Metz L, Oddone E, Edelman D. Foot education improves knowledge and satisfaction among patients at high risk for diabetic foot ulcer. The Diabetes Educator. 1999;25:560-7.

23. Vileikyte $L$, Rubin RR, Leventhal $H$. Psychological aspects of diabetic neuropathic foot complications: an overview. Diabetes Metab Res Rev. 2004;20 Suppl 1:S13-8.

24. Bell R, Arcury T, Snively B, Stafford J, Dohanish R, Quandt S. Diabetes foot self-care practices in a rural triethnic population. Diabetes Educ. 2005;31:75-83.

\section{Submit your next manuscript to BioMed Central and take full advantage of:}

- Convenient online submission

- Thorough peer review

- No space constraints or color figure charges

- Immediate publication on acceptance

- Inclusion in PubMed, CAS, Scopus and Google Scholar

- Research which is freely available for redistribution

Submit your manuscript at www.biomedcentral.com/submit 